\title{
SPECTRAL UNMIXING OF AIRBORNE HYPERSPECTRAL IMAGERY FOR MAPPING GIANT REED INFESTATIONS
}

\author{
Chenghai Yang ${ }^{1}$, Qian Du ${ }^{2}$, James H. Everitt ${ }^{1}$, John A. Goolsby ${ }^{1}$, and Nicolas H. Younan ${ }^{2}$ \\ ${ }^{1}$ USDA-ARS Kika de la Garza Subtropical Agricultural Research Center at Weslaco, TX, USA \\ ${ }^{2}$ Dept. of Electrical and Computer Engineering, Mississippi State Univ., Mississippi State, MS, USA
}

\begin{abstract}
Spectral unmixing techniques applied to hyperspectral imagery were examined for mapping giant reed (Arundo donax L.), an invasive weed that presents a severe threat to agroecosystems and riparian areas throughout the southern United States and northern Mexico. Airborne hyperspectral imagery with 102 usable bands covering a spectral range of 475-845 $\mathrm{nm}$ was collected from two giant reed-infested sites along the US-Mexican portion of the Rio Grande. The imagery was transformed with minimum noise fraction (MFN) to reduce the spectral dimensionality and noise. Linear spectral unmixing (LSU) and mixture tuned matched filtering (MTMF) were applied to the transformed MNF imagery based on endmember spectra extracted from the imagery. The abundance images were then converted into classification maps. For comparison, spectral angle mapper (SAM) and support vector machine (SVM) were used to classify the imagery. Accuracy assessment showed that MTMF was slightly better than or similar to LSU and that SVM performed better than the other three methods. The results from this study will be useful for distinguishing giant reed from associate plant species.
\end{abstract}

Index Terms - Linear spectral unmixing, mixture tuned matched filtering (MTMF), support vector machine (SVM), hyperspectral imagery, giant reed

\section{INTRODUCTION}

Giant reed (Arundo donax L.) is a bamboo-like perennial grass that grows 3 to 10 meters tall and spreads from horizontal rootstocks below the soil to form large colonies [1]. It typically grows in riparian areas and floodplains and can be found on wet stream banks, gravel bars, or dry banks away from permanent water [2]. Today giant reed is an invasive weed throughout the southern half of the United States and northern Mexico with the densest stands growing along the Rio Grande in Texas and the coastal rivers of southern California [3]. Giant reed consumes excessive amounts of water to supply its incredible rate of growth [4] and it displaces native vegetation, leading to the destruction of wildlife habitats [5]. Giant reed has become a major threat to riparian areas and watersheds in the Rio Grande Basin.

Accurate information on the spatial distribution and infested areas of giant reed is essential for effective management of this invasive weed. Remote sensing has the potential for providing timely and accurate information on the infestations of giant reed. Airborne multispectral imagery was evaluated for mapping giant reed infestations in Monterey County, California [6]. AVIRIS hyperspectral imagery was used for detecting and mapping giant reed in riparian areas in southern California [7]. The light reflectance characteristics of giant reed were described and the application of aerial color-infrared (CIR) photography and videography for detecting and mapping giant reed infestations in riparian areas in Texas was demonstrated [8]. More recently, high resolution satellite imagery has become available for remote sensing applications and provided new opportunities for effectively mapping invasive weeds. Both 2.8-m QuickBird and 10-m SPOT 5 satellite imagery have been evaluated for distinguishing giant reed infestations along the Rio Grande in southwest Texas [9-10]. The results showed that high resolution satellite imagery could be used to detect and map giant reed infestations as accurately as aerial photography and videography.

Although several types of remote sensing imagery have been evaluated for mapping giant reed, only limited work is conducted on the use of hyperspectral imagery for this invasive plant species. The objectives of this study were to evaluate linear spectral unmixing (LSU) and mixture tuned matched filtering (MTMF) for distinguishing giant reed and compare the results with those from spectral angle mapper (SAM) and support vector machine (SVM) classification techniques.

\section{METHODS}

This study was conducted along the US-Mexico portion of Rio Grande near Quemado, Texas. Two giant reed-infested areas, designated as sites 1 and 2, were selected for this study. Giant reed grows in association with woody and herbaceous vegetation on both sides of the river. The longitude and latitude coordinates near the centers of the sites were $\left(100^{\circ} 38^{\prime} 38^{\prime \prime} \mathrm{W}, 28^{\circ} 58^{\prime} 25^{\prime \prime} \mathrm{N}\right)$ for site 1 and $\left(100^{\circ} 39^{\prime} 18^{\prime \prime} \mathrm{W}, 29^{\circ} 01^{\prime} 20^{\prime \prime} \mathrm{N}\right)$ for site 2 . 
Hyperspectral imagery was acquired using an airborne hyperspectral imaging system [11]. The system consisted of a digital CCD camera, a hyperspectral filter, a front lens, and a PC computer equipped with a frame grabbing board and camera utility software. The camera was sensitive in the 280 to $1000 \mathrm{~nm}$ spectral range and has $1280(\mathrm{~h}) \times 1024(\mathrm{v})$ light-sensitive pixels. The effective spectral range of the system was from $457.2 \mathrm{~nm}$ to $921.7 \mathrm{~nm}$. The camera was configured to acquire 12-bit images with 128 spectral bands and a swath of 640 pixels.

A Cessna 206 single-engine aircraft with a camera port in the floor was used as the platform for image acquisition. No stabilizer or inertial measurement device was used to damper or measure platform variations, but care was taken to minimize the effects of winds and changes in the aircraft's speed and flight direction. The aircraft was stabilized at a predetermined altitude of $2438 \mathrm{~m}(8000 \mathrm{ft})$ above ground level, a speed of $178 \mathrm{~km} / \mathrm{h}(110 \mathrm{mi} / \mathrm{h})$, and a flight direction during the course of image acquisition for each site. A ground pixel size of approximately $2.0 \mathrm{~m}$ was achieved.

The geometric distortions due to movements in the across-track direction and variations in roll were corrected using a reference line approach for site 1 [11]. For the geometric restoration of the image for site 2, a curved road approximately along the flight direction was first identified in the raw image and an aerial CIR photo covering the imaging area was used as the reference image. The curved road in the aerial photo was digitized, rescaled and overlaid on the distorted road in the raw hyperspectral image. Selfdeveloped computer programs were used to perform the geometric corrections.

The geometrically restored hyperspectral images for the two sites were rectified to two respective georeferenced CIR photographs using rubber sheeting. The photographs were digitized and rectified to the Universal Transverse Mercator (UTM), World Geodetic Survey 1984 (WGS-84), Zone $14 \mathrm{~N}$, coordinate system based on a set of the ground control points located with a submeter-accuracy Global Positioning System (GPS) Pathfinder Pro XRS receiver (Trimble Navigation Limited, Sunnyvale, California). The procedure for image rectification was performed using ERDAS IMAGINE (Leica Geosystems Geospatial Imaging, LLC, Norcross, Georgia). Bands 1-5 and 108-128 (a total of 26 bands) were removed from each hyperspectral image and the remaining 102 bands with a spectral range of 475.3 to $845.5 \mathrm{~nm}$ were used for analysis.

The minimum noise fraction (MNF) transformation implemented in ENVI (Research Systems, Inc., Boulder, Colorado) was used to reduce the spectral dimensionality and inherent spectral noise in the hyperspectral imagery. Based on the eigenvalue plots and visual inspection of the MNF band images, the first 30 bands from the transformed MNF images were selected for image classification.

The major cover type classes for site 1 consisted of healthy giant reed, moisture-stressed giant reed with smaller and sparser plants, mixed woody and herbaceous vegetation, bare soil/roads, and water. The major classes for site 2 were similar to those at site 1 except that the stressed giant reed class was replaced by the giant reed regrowth class. Because of the variations within the classes, each major class was divided into more subclasses. There were a total of 12 subclasses for site 1 and 13 subclasses for site 2. For supervised training, different numbers of areas, or regions of interest, with known cover types were selected and digitized on each image as the training samples to represent respective subclasses or endmembers. These training areas were first verified on the ground with the aerial photographs and then selected on the hyperspectral images as training samples. The numbers of digitized training pixels ranged from 200 to 1571 among the subclasses for site 1 and from 424 to 2239 for site 2 . A boundary was defined for each site to exclude the areas outside the boundary for image classification.

Four supervised classification methods including linear spectral unmixing (LSU) [12], mixture tuned matched filtering (MTMF) [13], spectral angle mapper (SAM) [14], and support vector machine (SVM) [15] were applied to the two MNF images. The fully-constrained LSU abundance images were classified into the subclasses based on maximum abundance values. Similarly, the matched filtering (MF) score images were classified into the respective subclasses. The SAM classifier assigned pixels to the subclasses based on minimum spectral angles, while the SVM classifier classified pixels by selecting the highest probability. The subclasses within each classification map were then merged into the five defined classes. For accuracy assessment of the merged classification maps, 100 points were generated and assigned to the classes in a stratified random pattern for each site. The UTM coordinates of these points were determined and the GPS receiver was used to navigate to these points for ground verification. Error matrices for each classification map were generated by comparing the classified classes with the actual classes at these points. Overall accuracy, producer's accuracy, user's accuracy, and kappa coefficients were calculated based on the error matrices (Congalton and Green, 1999).

\section{RESULTS AND DISCUSSION}

Figures 1 and 2 show the CIR composite images derived from the hyperspectral images and the corresponding fiveclass classification maps based on the MTMF classifier for sites 1 and 2, respectively. On the CIR image, healthy giant reed has a distinct bright reddish color, stressed giant reed has a dark reddish tone, and giant reed regrowth after burning has a reddish brown color. Mixed dense woody and herbaceous vegetation show a dark reddish tone with variations among different species, sparse senescing grass and herbaceous species have a grayish to pinkish response, bare soil and roads have a light gray to white color, and water has a blue color. Although healthy giant reed had a 
distinct spectral response, the stressed giant reed had similar spectral response to mixed vegetation species as shown on the CIR images. Visual comparison of the five-class classification maps with the CIR images indicates that the giant reed and other cover types were well separated on the MTMF classification maps.

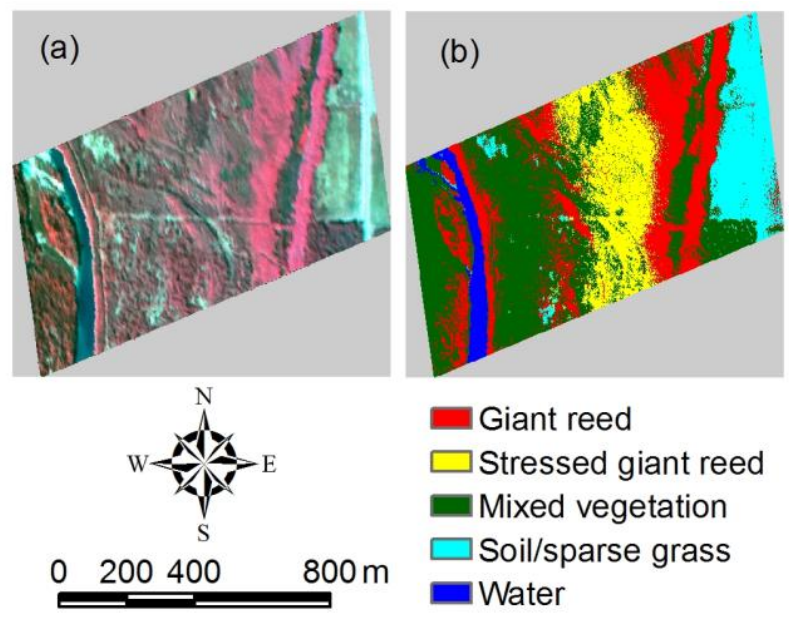

Fig. 1. (a) A color-infrared composite image derived from a 102-band hyperspectral image and (b) a MTMF-based fiveclass classification map generated from the 30-band MNF image transformed from the hyperspectral image of a giant reed-infested site near Quemado, Texas (Site 1).

Tables 1 and 2 summarize the accuracy assessment results for the classification maps generated from the 30band MNF images based on the four classifiers for sites 1 and 2, respectively. Overall accuracy ranged from $83 \%$ for LSU to $95 \%$ for SVM at site 1 and from $91 \%$ for SAM to $94 \%$ for SVM at site 2. SVM had the highest overall accuracy at both sites. MTMF had higher overall accuracy than LSU for site 1, whereas both LSU and MTMF had the same overall accuracy for site 2. SAM was comparable with either LSU or MTMF.

For site 1, SVM had a producer's accuracy of $96 \%$ and a user's accuracy of $100 \%$ for giant reed and a producer's accuracy of $100 \%$ and a user's accuracy of $90 \%$ for stressed giant reed. Among the four classifiers, SVM was the best for differentiating giant reed and stressed giant reed from the other cover types. MTMF had higher producer's accuracy, but lower user's accuracy than LSU for separating giant reed. Compared with LSU, MTMF maximizes the response of the defined endmembers on each endmember abundance image and therefore has the potential for more effectively differentiating the classes especially when the number of endmembers is large as in this study. All four methods successfully identified mixed vegetation, bare soil and water except that LSU had a low user's accuracy for mixed vegetation. For site 2, all classifiers successfully separated giant reed and giant reed regrowth from the associated cover types with producer's and user's accuracy values over $90 \%$. Again, all four classifiers sufficiently identified mixed vegetation, bare soil and water, but both LSU and SAM had low user's accuracy for mixed vegetation.
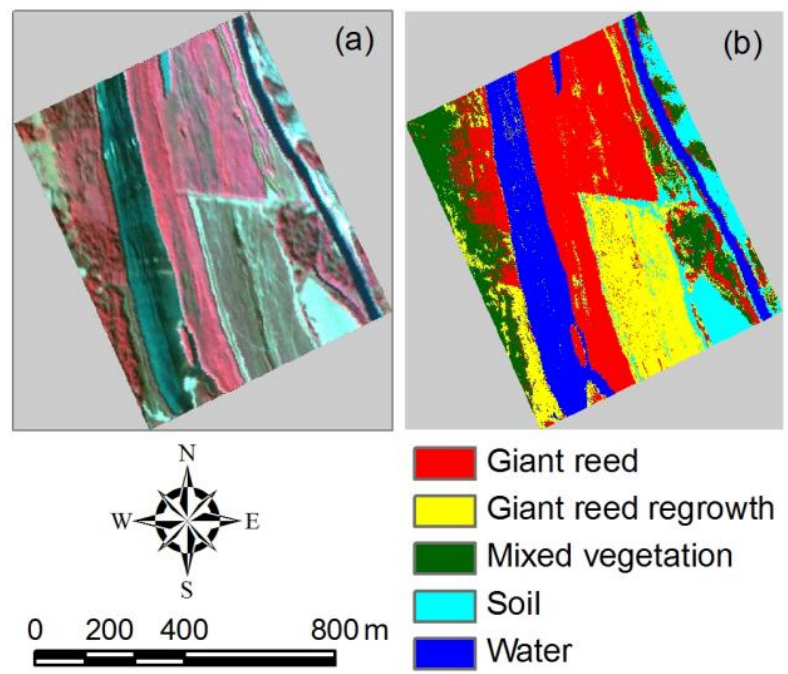

Fig. 2. (a) A color-infrared composite image derived from a 102-band hyperspectral image and (b) a MTMF-based fiveclass classification map generated from the 30-band MNF image transformed from the hyperspectral image of a giant reed-infested site near Quemado, Texas (Site 2).

Table 1. Accuracy assessment results for four classification maps generated from the 30-band minimum noise function (MNF) image transformed from a 102-band hyperspectral image of a giant reed-infested site near Quemado, Texas (Site 1)

\begin{tabular}{|c|c|c|c|c|c|c|c|c|c|c|c|c|}
\hline \multirow[t]{3}{*}{ Classifier $\dagger$} & \multirow{3}{*}{$\begin{array}{c}\text { Overall } \\
\text { accuracy } \\
(\%)\end{array}$} & \multirow{3}{*}{$\begin{array}{l}\text { Overall } \\
\text { kappa }\end{array}$} & \multicolumn{10}{|c|}{ Producer's accuracy (PA, \%) and user's accuracy (UA, \%) } \\
\hline & & & \multicolumn{2}{|c|}{ Giant reed } & \multicolumn{2}{|c|}{$\begin{array}{l}\text { Stressed giant } \\
\text { reed }\end{array}$} & \multicolumn{2}{|c|}{$\begin{array}{c}\text { Mixed } \\
\text { vegetation }\end{array}$} & \multicolumn{2}{|c|}{$\begin{array}{c}\text { Bare soil } \\
\text { /roads }\end{array}$} & \multicolumn{2}{|c|}{ Water } \\
\hline & & & PA & UA & PA & $\mathrm{UA}$ & PA & $\mathrm{UA}$ & $\mathrm{PA}$ & UA & PA & UA \\
\hline LSU & 83.0 & 0.782 & 75.0 & 100.0 & 76.5 & 86.7 & 92.0 & 62.2 & 80.0 & 100.0 & 90.0 & 90.9 \\
\hline MTMF & 88.0 & 0.845 & 92.9 & 81.3 & 76.5 & 86.7 & 92.0 & 85.2 & 80.0 & 100.0 & 100.0 & 100.0 \\
\hline SAM & 84.0 & 0.795 & 75.0 & 84.0 & 76.5 & 86.7 & 92.0 & 71.9 & 85.0 & 100.0 & 100.0 & 90.9 \\
\hline SVM & 95.0 & 0.936 & 96.4 & 100.0 & 100.0 & 89.5 & 92.0 & 88.5 & 90.0 & 100.0 & 100.0 & 100.0 \\
\hline
\end{tabular}

$\dagger \quad$ LSU $=$ linear spectral unmixing, MTMF = mixture tuned matched filtering, SAM = spectral angle mapper, and SVM $=$ support vector machine. 
Table 2. Accuracy assessment results for four classification maps generated from the 30-band minimum noise function (MNF) image transformed from a 102-band hyperspectral image of a giant reed-infested site near Quemado, Texas (Site 2)

\begin{tabular}{|c|c|c|c|c|c|c|c|c|c|c|c|c|}
\hline \multirow[t]{3}{*}{ Classifier $\dagger$} & \multirow{3}{*}{$\begin{array}{c}\text { Overall } \\
\text { accuracy } \\
(\%)\end{array}$} & \multirow{3}{*}{$\begin{array}{l}\text { Overall } \\
\text { kappa }\end{array}$} & \multicolumn{10}{|c|}{ Producer's accuracy (PA, \%) and user's accuracy (UA, \%) } \\
\hline & & & \multicolumn{2}{|c|}{ Giant reed } & \multicolumn{2}{|c|}{$\begin{array}{l}\text { Giant reed } \\
\text { regrowth }\end{array}$} & \multicolumn{2}{|c|}{$\begin{array}{c}\text { Mixed } \\
\text { vegetation }\end{array}$} & \multicolumn{2}{|c|}{$\begin{array}{l}\text { Bare soil } \\
\text { /sparse grass }\end{array}$} & \multicolumn{2}{|c|}{ Water } \\
\hline & & & PA & UA & PA & UA & PA & UA & PA & UA & PA & UA \\
\hline LSU & 93.0 & 0.908 & 91.7 & 97.1 & 100.0 & 95.5 & 88.9 & 61.5 & 76.9 & 100.0 & 100.0 & 100.0 \\
\hline MTMF & 93.0 & 0.908 & 91.7 & 94.3 & 100.0 & 91.3 & 88.9 & 72.7 & 76.9 & 100.0 & 100.0 & 100.0 \\
\hline SAM & 91.0 & 0.882 & 91.7 & 91.7 & 90.5 & 95.0 & 88.9 & 61.5 & 76.9 & 100.0 & 100.0 & 100.0 \\
\hline SVM & 94.0 & 0.921 & 94.4 & 94.4 & 100.0 & 91.3 & 88.9 & 80.0 & 76.9 & 100.0 & 100.0 & 100.0 \\
\hline
\end{tabular}

$\dagger$ LSU $=$ linear spectral unmixing, MTMF $=$ mixture tuned matched filtering, SAM $=$ spectral angle mapper, and SVM $=$ support vector machine.

\section{CONCLUSIONS}

The results from this study have demonstrated that airborne hyperspectral imagery in conjunction with image transformation and classification techniques can be useful for mapping giant reed infestations. MNF transformation applied to hyperspectral imagery can significantly reduce the number of bands needed for image classification. Because of the spectral variations within classes, it is necessary to use multiple endmembers for each class for spectral unmixing and classification. Between the two spectral unmixing techniques, MTMF was slightly better than or similar to LSU for differentiating giant reed from the associated cover types. In comparison, SAM was similar to LSU and MTMF, while SVM produced the best classification results among the four classifiers examined.

\section{REFERENCES}

[1] T.L. Dudley, "Arundo donax," In: C.C. Bossard, J.M. Randal, and M.C. Hosovsky (eds.) Invasive Plants of California Wildlands, University of California Press, Berkeley, California, p. 53-58, 2000 .

[2] M. Newhouser, C. Cornwall, and R. Dale, Arundo: A Landowner Handbook, Sonoma Ecology Center and California State University, Sacramento, California, 22 p., 1999.

[3] G.P. Bell, "Ecology and management of Arundo donax and approaches to riparian habitat restoration in southern California," In: J.H. Brock, M. Wade, P. Pysek, and D. Green (eds.) Plant Invasion Studies from North America and Europe, Blackhuys Publishers, Leiden, The Netherlands, p. 103-113, 1997.

[4] M.E. Iverson, "The impact of Arundo donax on water resources," In: N.E. Jackson, P. Frandsen, and S. Douthit (eds.) Arundo donax Workshop Proceedings, Ontario, California, p. 1925, 1994.

[5] J. Khudamrongsawat, R. Tayyar, and J.S. Holt, "Genetic diversity of giant reed (Arundo donax) in the Santa Ana River, California," Weed Science 52: 395-405, 2004.
[6] A.J. Oakins, "An assessment and management protocol for Arundo donax in the Salinas Valley Watershed," Thesis, California State University, Monterey Bay, California, 50 p., 2001.

[7] D. Dipietro, S.L. Ustin, and E. Underwood, "Mapping the invasive plant Arundo donax at Camp Pendleton Marine Base using AVIRIS," In: Proc. 10th JPL Airborne Visible Infrared Imaging Spectrometer (AVIRIS) Workshop, Jet Propulsion Lab, Pasadena, California, 2002.

[8] J.H. Everitt, C. Yang, M.A. Alaniz, M.R. Davis, F.L. Nibling, and C.J. Deloach, "Canopy spectra of giant reed and associated vegetation," Journal of Range Management 57: 561-569, 2004.

[9] J.H. Everitt, C. Yang, and C.J. Deloach, "Remote sensing of giant reed with QuickBird satellite imagery," Journal of Aquatic Plant Management 43(2): 81-84, 2005.

[10] J.H. Everitt, C. Yang, C., R.S. Fletcher, and C.J. Deloach, Jr., "Comparison of QuickBird and SPOT 5 satellite imagery for mapping giant reed," Journal of Aquatic Plant Management 46: 77-82, 2008.

[11] C. Yang, J.H. Everitt, M.R. Davis, and C. Mao, "A CCD camera-based hyperspectral imaging system for stationary and airborne applications," Geocarto International 18(2): 71-80, 2003.

[12] J.B. Adams, M.O. Smith, and P.E. Johnson, "Spectral mixture modeling: A new analysis of rock and soil types at the Viking Lander 1 site," Journal of Geophysical Research 91: 8098-8112, 1986.

[13] J.C. Harsanyi and C.I. Chang, "Hyperspectral image classification and dimensionality reduction: An orthogonal subspace projection approach," IEEE Transactions on Geoscience and Remote Sensing 32: 779-785, 1994.

[14] F.A. Kruse, A.B. Lefkoff, J.W. Boardman, K.B. Heidebrecht, A.T. Shapiro, J.P. Barloon, and A.F.H. Goetz, "The spectral image processing system (SIPS): Interactive visualization and analysis of imaging spectrometer data," Remote Sensing of Environment 44(23): 145-163, 1993.

[15] C.-W. Hsu, C.-C. Chang, and C.-J. Lin, "A practical guide to support vector classification," National Taiwan University, 2007, URL http://ntu.csie.org/ cjlin/papers/guide/guide.pdf. 